\title{
Choices to be made
}

\author{
Local and regional authorities are making climate-conscious choices, whilst climate change impacts will \\ soon mean individuals need to make choices to survive.
}

The breaking off of a large piece (over $5,800 \mathrm{~km}^{2}$ ) of the Larson-C Ice Shelf has dominated the news headlines of late - a widening crack spread closer to the edge of the shelf, finally reaching the edge and freeing the iceberg on 12 July 2017 . The dramatic and trackable event played out over weeks. It came in the aftermath of President Trump's announcement of the US withdrawal from the Paris Agreement and in the lead up to a G20 climate discussion meeting.

The G20 meeting, held in Hamburg, Germany, concluded with a statement in which 19 of the 20 nations affirmed their commitment to the Paris Agreement, citing that the agreement was 'irreversible'. The US stands apart from this group, and considering the situation more broadly with Nicaragua and Syria, the only other nations not committing to the Paris Agreement.

Whether there will be a softening of the US stance is yet to be seen but it is heartening to see commitments from states and cities within the US stepping up to mitigate emissions while the federal government steps back. As Mark Watts, executive director of C40, writes in a Commentary (page 537) "Mayors of the world's cities understand that there is no alternative to urgent, bold and transformative action against climate change. By the end of 2020, every C40 city will have a plan in place to ensure they can deliver on their obligations to the Paris Agreement." In a related Feature (page 543), Erica Gies investigates the role of businesses, as a number of large corporations are making commitments in line with the Paris Agreement, supporting the work of cities and states.

To track progress and ensure countries and other committed parties are meeting their ambitions we need reliable data on emissions, which requires research funding and observing platforms. Mitigation commitments will hopefully also translate into funding to support these efforts. Another point to be considered is quantifying the baseline temperature from which warming will be measured, as discussed by Andrew Schurer and

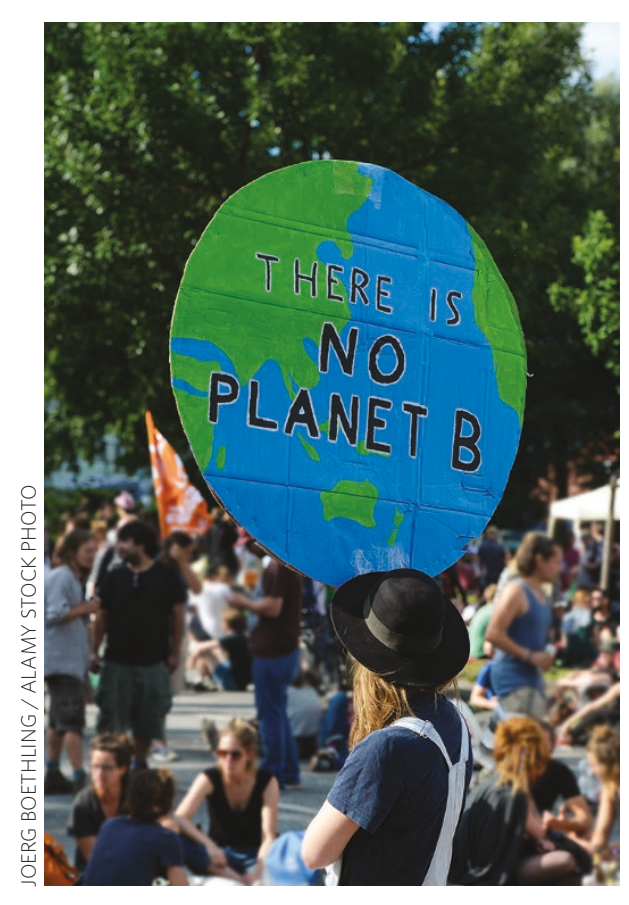

The situation in California is one example but, as has been reported in the literature, extremes of natural climate cycles are likely to increase, with El Niño having potentially far-reaching consequences due to its influence across the globe. Whilst the predictions are no longer suggesting there will be an El Niño event later this year, the warmer-thanaverage sea-surface temperatures in the west Indian Ocean and the cooler-thanaverage temperatures in the east suggest a shift to a positive Indian Ocean dipole event. Positive Indian Ocean dipole is associated with extreme droughts in the eastern Indian Ocean nations and maritime continent, whilst if there is, as predicted, a positive Indian Ocean dipole this year, the drought-ravaged regions of Sudan and tropical eastern Africa could be hit by extreme rainfall, potentially leading to flooding and landslides (Cai et al. Nature 510, 254-258; 2014). This is a situation mirroring hydrological extremes seen in California, but in developing nations with less capacity to cope with such events.

colleagues (page 563). The Paris Agreement aims to limit warming to $1.5^{\circ} \mathrm{C}$, but the pre-industrial temperature has not been defined and this Letter discusses the implications of different choices for likelihood and timing of exceedance of temperature targets, as well as allowable carbon emissions.

Action is needed: states and cities will have to, and are already starting to, deal with the consequences of a changing climate. California and China are discussing climate cooperation, with California all too aware of the challenges it will face having already experienced a number of years of extreme drought. The intensification of the hydrological cycle is discussed by Simon Wang and colleagues in a recent Commentary using recent events in California as an example (Nat. Clim. Change 7, 456-458; 2017). This change from extreme drought in 2012-2016 to extreme flooding over the 2016-2017 Californian winter is an example of anomalous circulation patterns that can persist and then flip, with such extremes being emphasized under climate change. inundation from sea-level rise and storm surge. A recent study looks at the lower 48 states of the USA and which coastal communities are suffering chronic flooding and inundation (Aton, A. Scientific American http://go.nature. com/2u11YVi; 12 July 2017). The results show that over 90 communities already face chronic inundation, with the number projected to rapidly increase, dependent on emissions in the coming years. These communities will require fortification and adaptation to remain, or they will be forced to relocate.

The choice to abandon is not an easy one to make and an Article in this issue, and featured on the cover (page 581), investigates the choices being made by residents on four low-lying islands of the Philippines. These residents have chosen to remain and adapt despite a relocation plan being developed by the authorities. This is a choice that will hopefully be available to, but not needed by, others as the impacts of climate change continue to spread.
Another example is flooding and 